\title{
Modern problems in assessment of hydraulic resistance
}

\author{
Igor Sikarev ${ }^{1}$, Tatiana Vekshina $^{1}$, Vladimir Bolshakov ${ }^{1}$, Ekaterina Korinets $^{1}$, and Artem \\ Butsanets $^{2, *}$ \\ ${ }^{1}$ Russian State Hydrometeorological University, Malookhtinsky ave., 98, Saint-Petersburg, Russia, \\ 195196 \\ ${ }^{2}$ Admiral Makarov State University of Maritime and Inland Shipping, 5/7, Dvinskaya Street, Saint- \\ Petersburg, 198035, Russia
}

\begin{abstract}
The paper is devoted to the analysis of modern problems in assessment of hydraulic resistance. The obtained formulas for calculating the roughness coefficients and other interrelated hydraulic parameters of the channel are given. As a determining factor for the systemic characteristics of flows, N.A. Rzhanitsyn used the average long-term and average maximum water discharges, and the authors of this work proposed the use of these characteristics in accordance with the watershed area A in $\mathrm{km} 2$ of the subsequently derived dependences for unexplored rivers. Thanks to this approach, it became possible to obtain information by cartographic methods. Direct approximation of these data gives an expression for the flow order. The formulas obtained can be used to calculate the hydraulic characteristics of lowland rivers. For the European territory of Russia, the formulas have been tested using independent field information. However, the authors believe that the formulas will successfully work for other even lands as well. The formulas are simple and easy to calculate using software. In the future, it is planned to use specialized software for processing calculations and use the obtained results in the geographic information system.
\end{abstract}

\section{Introduction}

Hydraulic resistance is a key problem of both technical and river hydraulics. On their basis, calculations of various parameters of channel flows and elements of hydraulic structures are performed. At the present stage of development of science and technology, the need to improve the reliability of such calculations is of particular relevance due to the increasing scale of landscape ecology control and the implementation of a monitoring system for water bodies [1], including using autonomous vessels [2]. Increasingly, digital models of the seabed relief are being built [3], including using satellite altimetric observations [4], modeling of complex underwater landscapes in order to more accurately predict the erosion and destruction of hydraulic structures [5], and the degree of influence of plant roots [6-8] on morphodynamics is estimated. Comparison of two-dimensional and

\footnotetext{
*Corresponding author: butsanetsaa@gumrf.ru
} 
three-dimensional flow models [9-10] is carried out. The influence of large wood in the river bed is taken into account in these models [11]. Therefore, the automation of calculations of hydraulic processes based on computer technology is one of the most important applied problems of modern earth science [12-13].

Due to the multifactorial dependence of hydraulic resistance, most of the methods are imperfect. It requires deep analysis and understanding of calculation methods and leads to the need for further developments in order to take into account various factors.

\section{Methods and materials}

The use of Velikanov's parameter opens up the possibility of using observations from previous years and studying the influence of other factors on the channel capacity [12].

A consistent approach to the study of the regularities of channel formation and its relationship with the physical and geographical environment has become generally accepted. Channel processes, including hydraulic resistance, cannot be considered as a chain of phenomena, the development of which occurs in isolation from the geographic environment, without taking into account specific features that characterize the watershed basin landscape. Flows and their watershed must be considered in close relationship and interdependence. Hydraulic resistance is a key problem of both technical and river hydraulics. On their basis, calculations of various parameters of channel flows and fragments of hydraulic structures are performed [2]. Taking into account the dependence of channel processes on the position of rivers in geographic zones, landscape and climatic conditions is of particular importance. Consideration of the lithological structure of river valleys and the hydrological regime of rivers is one of the foundations of the hydromorphological theory of channel processes. To characterize the hydraulic resistance of overgrown channels, it was proposed to consider the Velikanov's parameter. Its particular value lies in the fact that it can be determined directly from hydrometric data [14]. On this basis, calculation formulas were obtained to assess the hydraulic resistance of overgrown rivers. The proposed formulas are obtained as a result of the transition from the hydraulic characteristics of overgrown channels to the corresponding landscape and climatic factors, which allows them to be used for assessing the hydraulic resistance of overgrown channels in different climatic zones. Velikanov's parameter is of particular importance in river hydraulics and hydrometry. It acts as a system characteristic of the hydraulic resistance of the channel flow, i.e. is one of the main characteristics of the channel capacity. [14]. For free channels, Velikanov's parameter is:

$$
m_{0}=\frac{\sqrt{I}}{n_{0}},
$$

where mo - Velikanov's parameter for a free channel; no - roughness coefficient of a free channel; I - slope [15].

Velikanov's parameter can be obtained on the basis of hydrological and morphological characteristics of river systems. The generalization of the results obtained and the substantiation of the admissibility of their extension to unexplored objects is of great scientific and practical importance. Such a possibility is caused by the use of the regularities of changes in the hydromorphological characteristics of river systems. In their structure, each separately taken river is considered as a link - a flow of a fixed order N. It turned out to be expedient to accept the system of these orders proposed by N. A. Rzhanitsyn.

In the structure of river systems, the dependence of morphometric characteristics on the orders of the $\mathrm{N}$ flow is established, with their increase from sources to the mouth, and the 
orders themselves are determined by the water content of the river. If the runoff has not been studied, these characteristics, ultimately, can be put in accordance with the watershed area $\mathrm{A}(\mathrm{km} 2)$ [5].

It should be emphasized the special role of the slope of the free surface. It is equal to the average slope of the bottom if uniform motion is considered over a sufficiently long section. In the systemic aspect, this slope not only serves as a measure of energy losses for flow movement, but also reflects the geomorphological conditions of the river basin, the nature of the soils from which the channel is composed, and, consequently, its roughness. Moreover, this element is closely related to the order of flows and, ultimately, to the hydrological and hydrographic characteristics of river systems.

Results. As a determining factor for the systemic characteristics of flows, N.A. Rzhanitsyn took the average long-term Qav and the average maximum water flow Qmax. But we, having in mind the use of the dependencies deduced in the future in relation to unexplored rivers, will put these characteristics in accordance with the watershed area $\mathrm{A}$ in $\mathrm{km} 2$, which can always be obtained by cartographic methods. A direct approximation of this data gives an expression for the flow order:

$$
N=4.4 A^{0.09}
$$

For the general slope of the free surface (bottom) under the assumption of quasiuniform flow motion:

$$
I=0.012 / A^{0.44}
$$

The average particle diameter $\mathrm{d}$ of the bottom soils serves as a natural characteristic of the roughness of river channels. In the last century, the general acceptance was gained by the dependence proposed by Strickler for the roughness coefficient:

$$
n_{0}=\kappa_{r} d^{1 / 6}
$$

The analysis carried out by Raudkivi evealed quite wide ranges of change in the coefficient $\mathrm{kr}=0.015-0.07$. More definite is the value of $\mathrm{kr}$ established by V.M. Makkaveev for channel flows forming their own roughness: $\mathrm{kr}=0.03$. We will take this value in our further consideration of the problem.

Thus, to determine the roughness coefficient, it is sufficient to know the value of $\mathrm{d}$. However, data on the size of the river bed soils are extremely contradictory and insufficient. But there is information about the Lokhtin coefficient 1, systematized by M.I. Makkaveev on the basis of field studies of survey parties of the river fleet. These unique data are cited by N.A. Rzhanitsyn.

It is a known fact that the Lokhtin number is the ratio of the particle diameter $\mathrm{d}$ in $\mathrm{mm}$ to the inclination of the water surface $\Delta \mathrm{z}$ in $\mathrm{m}$ per $\mathrm{km}$ :

$$
l=\frac{d}{\Delta z}
$$

Some values of this characteristic, systematized and put in accordance with the orders of river flows and watershed areas, are given in the table.

Table 1. Slope, particle diameter and Lokhtin number depending on flow order and watershed area.

\begin{tabular}{|l|l|l|l|l|}
\hline $\mathrm{N}$ & $\mathrm{A}$, in $\mathrm{km}^{2}$ & $\mathrm{I}$, in $\% 00$ & $\mathrm{~d}$, in $\mathrm{mm}$ & 1 \\
\hline $\mathrm{VI}$ & 50 & 2.35 & 5.6 & 2.4 \\
\hline
\end{tabular}




\begin{tabular}{|l|c|c|c|c|}
\hline VIII & 1000 & 0.69 & 1.47 & 2.1 \\
\hline XI & 22500 & 0.14 & 0.42 & 3.0 \\
\hline
\end{tabular}

The logarithmic approximation of the table data allows obtaining the dependence:

$$
d=1426 I^{0.92}
$$

which corresponds to the expression:

$$
n_{0}=0.1 I^{0.153}
$$

Expression (7) is established directly from formula (4) at $\mathrm{k}_{\mathrm{r}}=0.03$. After substituting I by (3), we obtain:

$$
n_{0}=0.11 / A^{0.067}
$$

\section{Discussion}

The obtained formulas can be used to calculate the hydraulic characteristics of lowland rivers. For the European territory of Russia, the formulas have been tested using independent field information. However, the authors believe that the formulas will successfully work for other even lands as well. More clarifications are needed for mountainous areas.

The formulas are simple and convenient for computer technology calculations, which is very important for modern science and technology. In the future, it is planned to use the patented program [6] to process calculations and implement the results obtained in the Geographic Information System.

Government bodies need to use geographic information systems to solve such problems as performing operational calculations, assessing water resources and studying the hydrological regime of water bodies. This problem is especially acute due to the regular reduction in the number of hydrological stations on the territory of the Russian Federation, as well as in many foreign countries.

Digital maps of water bodies, together with their hydrological characteristics and measurement data in GIS, make it possible to quickly perform an automated comprehensive analysis of the ongoing processes, and therefore, more efficiently collect, process and systematize data, on the basis of which the design and construction of hydraulic structures is carried out, as well as preparation for making management decisions.

\section{Conclusions}

The obtained formulas are generalized system-zonal dependencies, since they are based on the hydromorphological characteristics of river systems, i.e. on the most general information contained in the publications of the water cadastre and data banks of modern geophysical information systems. As a result, it becomes possible to estimate the bandwidth of the channel of unexplored rivers. For each specific control section, the values of the roughness coefficients are calculated with varying degrees of approximation. But in comparison with the corresponding descriptive scales of roughness, the quantitative definiteness of the obtained dependences gives every reason for their preference.

This is exactly the result that allowed us to further evaluate the roughness coefficients and the Velikanov's parameter of the channels of unexplored rivers. As a result of the 
transition from hydraulic characteristics to the corresponding landscape and climatic factors, their generalized estimates were obtained for different rivers and climatic zones.

\section{References}

1. T. V. Vekshina, Eurasian Scientific Association 4-6(50), 407-409 (2019)

2. V. Karetnikov, et al., Technology Level and Development Trends of Autonomous Shipping Means, Energy Management of Municipal Transportation Facilities and Transport, 421-432 (Springer, Cham, 2019) DOI: 10.1007/978-3-030-57450-5_36

3. I. Laks, et al., Water 9(4), 283 (2017) doi.org/10.3390/w9040283

4. L. Jiang, H. Madsen, P. Bauer-Gottwein, Remote sensing of environment 225, 229-247 (2019) 10.1016/j.rse.2019.03.014

5. K. Roushangar, M. T. Alami, S. M. Saghebian, Journal of Hydroinformatics 20(2), 356-375 (2018) 10.2166/hydro.2018.020

6. F. Caponi, A. Siviglia, Geophysical Research Letters 45(17), 9013-9023 (2018) 10.1029/2018GL078696

7. R. I. Ferguson, R. J. Hardy, R. A. Hodge, Earth Surface Processes and Landforms 44(12), 2437-2449 (2019) 10.1002/esp.4673

8. R. I. Ferguson, et al., Water Resources Research 53(3), 2278-2293 (2017) 10.1002/2016WR020233

9. E. F. Najafabadi, H. Afzalimehr, Iranian Journal of Science and Technology, Transactions of Civil Engineering, 1-10 (2019) 10.1007/s40996-019-00298-4

10. M. A. Samine, et al., Geophysical Research Letters 46(12), 6534-6543 (2019) 10.1029/2019GL082986

11. S. Addy, M. E. Wilkinson, Wiley Interdisciplinary Reviews: Water 6(6), e1389 (2019) $10.1002 /$ wat2.1389

12. V. A. Bolshakov, Information technologies in applied problems of hydraulics, Prospects for the development of science and education: a collection of scientific papers based on the proceedings of the XXVII international scientific and practical conference, 231-233 (IE Tugolukov A.V., Moscow, 2018)

13. H. Wang, et al., Energy Conversion and Management 56, 113-129 (2018) 10.1016/j.enconman.2017.10.078

14. I. F. Karasev, T. V. Vekshina, Izvestiya of VNIIG named after B.E. Vedeneev 245, 101-108 (2006)

15. E. M. Korinets, A program for visualizing graphical dependencies based on experimental studies of the effect of interaction between channel and floodplain flows on the transport of bottom sediments. Certificate of registration of the computer program RU 2018610821, 18.01.2018, Application 2017662126 (2017) 